\title{
A PERSPECTIVA DISCENTE SOBRE OS RESÍDUOS SÓLIDOS EM UMA ESCOLA DO SEMIÁRIDO NORDESTINO
}

\author{
Carla Manoela Costa Rodrigues ${ }^{1}$ e Marcelo Campêlo Dantas ${ }^{2}$
}

\section{RESUMO}

O presente trabalho teve como objetivo analisar a percepção dos estudantes de uma escola da rede pública de ensino sobre os resíduos sólidos no âmbito da educação ambiental. Para a coleta de dados foi aplicado um questionário destinado a 90 alunos do ensino médio do município de Crateús - CE. Os resultados demonstraram que a maioria (64\%) dos estudantes vê o lixo como algo inútil. Boa parte dos alunos (69\%) conheceu o tema "lixo" nas aulas de biologia, porém, a frequência de aulas que abordam a temática é considerada baixa. Os projetos e ações governamentais são os meios mais referidos na sensibilização, e a minimização do lixo deve ocorrer por meio de ações sustentáveis, segundo os estudantes. Apesar dos discentes conhecerem certas condutas sustentáveis, ainda não estão inteirados da realidade social caracterizada pela produção de lixo.

Palavras-chave: Resíduos Sólidos. Lixo. Percepção dos Estudantes. Educação Ambiental.

\section{ABSTRACT}

The present work had the objective of analyzing the perception of students of a school in the public system on solid waste in the scope of environmental education. Data collection was done through a semi-structured questionnaire to 90 high school students. The results showed that the majority (64\%) of the students see the trash as something useless. Most of the students (69\%) knew the subject "junk" in biology classes, however, the frequency of classes that approach the subject is considered low by them. It is observed that although the students know some concepts and sustainable behaviors, they still present a simplistic view on the problem of garbage, and they have little information regarding the social reality that characterizes the solid waste production.

Keywords: Solid Waste. Garbage. Perception of students. Environmental Education.

\footnotetext{
${ }^{1}$ Graduada em Ciências Biológicas pela Universidade Estadual do Ceará-UECE.

${ }^{2}$ Mestre em Bioquímica pela Universidade Federal do Ceará-UFC. Professor na Universidade Estadual do Ceará-UECE.
} 
AMBIENTE \& EDUCAÇÃO

ISSN- 1413-8638

E-ISSN - 2238-5533

v. 23, n. 1, p. 122- 139, 2018

\section{Introdução}

A revolução industrial trouxe consigo uma crescente demanda de valores consumistas que levaram ao homem interferir na natureza, se apoderando do direito de manipular o meio ambiente de acordo com suas necessidades; estas impostas pelo modelo de consumo social (ROTH; GARCIAS, 2008). Uma das problemáticas enfrentadas atualmente pela sociedade é a produção de resíduos sólidos, popularmente denominado de lixo (PIAZ; FERREIRA, 2011). Antigamente, este não era visto como um problema devido aos materiais que o constituíam, pois eram degradados facilmente pela ação da natureza (CARARO, et al., 2008).

A presença do lixo é cada vez mais significativa nas áreas urbanas, e o seu lançamento em locais inadequados pode gerar impactos ambientais que modificam ou prejudicam o equilíbrio do ecossistema (FERREIRA; ANJOS, 2001). Porém, o problema em torno dos resíduos sólidos não está baseado apenas na preocupação da destinação correta. Envolve principalmente a ética social na diminuição dos resíduos sólidos, que por sua vez se dá por intermédio da sensibilização e informação, ou seja, uma educação ambiental crítica (NAVARRO, 2014).

A produção de resíduos sólidos tem recebido especial destaque na atualidade. Seu crescimento não se deve apenas ao aumento populacional, mas sim ao padrão capitalista da lógica de consumo exacerbado, utilizado como escolha de estilo de vida (FERNANDES, 2014). O consumismo desenfreado leva a um acúmulo desnecessário de bens e consequente, produção de resíduos que prejudicam o meio ambiente e o ser humano (ZANETI; SÁ, 2002).

O modelo consumista atual se caracteriza pela precária sustentabilidade ambiental vigente na sociedade, a educação ambiental supre as dificuldades encontradas neste; com conscientização de práticas ecologicamente mais corretas, sendo essas menos prejudiciais ao meio ambiente. As atitudes coerentes, sobretudo as de consumo, devem possuir caráter correto para com o meio ambiente, tendo a população uma formação sobre a educação ambiental e seus pressupostos (FRANCO, 2014). 
As instituições de ensino têm uma influência fundamental para esse processo. A educação ambiental é inserida nesses locais destinados à instrução dos homens para suprir os problemas ambientais existentes no mundo contemporâneo (OLIVEIRA, 2006). O meio acadêmico deve estar integrado com todos os segmentos da sociedade, por isso, a questão do lixo deve ser discutida nas escolas para haver conhecimentos significativos e postos em prática nas ações sociais (DIAS et al., 2014).

Desse modo, é perceptível a necessidade de analisar os significados que os estudantes dessa escola apresentam sobre os resíduos sólidos e os aspectos relacionados a estes. Assim, segundo Razzia e Biasus (2015) as pesquisas que são voltadas para a investigação do meio ambiente são importantes no período atual em que a sociedade se encontra, pois, o cenário global se caracteriza por uma extensa discussão sobre a apreensão existente com as consequências da cultura do consumo e desperdício existente na sociedade.

\section{Materiais e métodos}

Área de pesquisa

Cidade de Crateús - CE

Crateús é um munícipio pertencente ao estado do Ceará, localizada na macrorregião do sertão dos Inhamuns, fundada em 1880 pela Lei de Criação Decreto 3.012. Está situada na região oeste, apresenta Latitude 05 10'42"S e Longitude 4040'39”W, com área territorial de 2.985,41 km². Os municípios limítrofes são Tamboril, Ipaporanga, Novo Oriente, Independência, Poranga e o Estado do Piauí a oeste. A cidade possui uma população de aproximadamente 74. 271 habitantes, sendo $72,30 \%$ presente na zona urbana e $27,70 \%$ na zona rural (IPECE, 2015).

Local de estudo 
O colégio em que se desenvolveu a pesquisa está localizado na zona urbana cidade de Crateús - CE. A escola atende ao ensino médio (do $1^{\circ}$ ao $3^{\circ}$ ano) nos turnos manhã, tarde e noite. A escolha da Instituição para a realização do levantamento de dados foi motivada por relatos de experiências outrora sucedidos sobre o tema. A realização da pesquisa foi possível através da anuência disponibilizada pela direção da escola, pela professora que leciona a disciplina de Biologia e pelos discentes participantes da pesquisa. Por questões éticas preferiu-se não citar o nome da instituição e dos colaboradores.

\section{Tipologia da pesquisa}

A pesquisa científica é um meio utilizado para gerar conhecimento e responder questões de problemas existentes e estabelecidos pelo pesquisador, trata-se de um processo com etapas e habilidades apropriadas para se atingir os objetivos delimitados (CAMPOS et al., 2009).

O presente trabalho constitui-se como pesquisa qualitativa devido tratarse de um estudo e análise das concepções de estudantes (BAUER; GASKELL, 2002). Na abordagem qualitativa realiza-se a interpretação das informações presentes na coleta dos dados obtidos no local da pesquisa (PRODANOV; FREITAS, 2013).

A pesquisa tem abordagem qualitativa do tipo estudo de caso, a qual consiste na coleta e diagnóstico dos dados coletados, baseando-se na delimitação de uma determinada questão e suas variáveis que surgem no decorrer da pesquisa, de modo a se utilizar de pressupostos teóricos que condizem e auxiliam na explicação das informações coletadas (YIN, 2001). Trata-se de um método investigativo de cunho objetivo e aprofundado, em que pode ser destinado ao estudo individual ou grupo de pessoas sobre uma questão específica que se visa investigar (PRODANOV; FREITAS, 2013).

Coleta de dados 
A pesquisa foi realizada através de um questionário, pois de acordo Chaer, Diniz e Ribeiro (2011), este instrumento representa uma ferramenta importante na coleta de informações, pois é um método prático que possibilita maior uniformização e manejo de dados. O questionário consiste em "[...] um instrumento de coleta de dados, constituído por uma série ordenada de perguntas" (MARCONI; LAKATOS, 2003, p. 201). O questionário continha perguntas referentes ao tema resíduos sólidos. A aplicação ocorreu no mês de junho, no ano de 2016. Um montante de 90 discentes participou, sendo estudantes do $1^{\circ}, 2^{\circ}$ e $3^{\circ}$ anos do ensino médio do ensino regular.

\section{Resultados e discussão}

A percepção dos entrevistados sobre a definição do lixo foi bastante diversa, entretanto, a maior parte (64\%), definiu lixo como algo inútil, sem nenhuma serventia após sua utilização primeira. Em pesquisas realizadas por Boff, Araújo e Boff (2009) e outra por Alencar (2005), foi possível averiguar resultados similares, onde os alunos, em sua maioria, associam o lixo a materiais que não se utilizam mais e que são jogados fora. Para Oliveira e colaboradores (2011), as pessoas correlacionam o lixo ao que não serve, por este representar um material sem fins lucrativos e que não pode ser reciclado.

A visão sustentável pôde ser vista nas respostas de $14 \%$ dos discentes. Para estes, o lixo é algo reutilizável, pode ser reaproveitado, sendo matéria prima na confecção de outros materiais. Trechos das respostas dos entrevistados serão nomeados pelas siglas "R1", "R2" ..., para representação dos resultados:

É um certo material que quando usado é descartado, mas pode ser reutilizado $(\mathrm{R} 1)$.

Lixo é tudo aquilo que pode ser reciclado (R2).

Resultados semelhantes foram encontrados no trabalho de Razzia e Biaus (2015), onde a representação do lixo foi vista interligada a conceitos relacionados à sustentabilidade. Na percepção dos autores citados, isso ocorre devido à força que essa ideia vem ganhando na atualidade, devido os 
fatores sociais que influenciam nas ações comportamentais e na reflexão das pessoas com o meio ambiente.

Para Boff, Araújo e Boff (2009) os discentes que demonstram uma visão do lixo ligada a concepções sustentáveis, demonstram indício de um começo no processo de sensibilização relacionado à conscientização ambiental.

Para uma parcela de $10 \%$ dos entrevistados, o lixo é algo prejudicial à natureza e à saúde dos seres humanos, como observado nas respostas seguintes:

É um produto orgânico formado pelos seres humanos, que pode prejudicar a saúde (R3).

Tudo aquilo que é jogado fora e prejudica o meio ambiente (R4).

São restos de resíduos sólidos, que quando em contato com a natureza geram amplos problemas ambientais e demoram a se decompor (R5).

Rêgo, Barreto e Killinger (2002) em estudos, observaram que a relação do lixo à transmissão de doenças; representa um fator observado na fala de um determinado grupo de pessoas, sendo essa percepção, condizente com o que a literatura aborda.

De acordo com achados de Cortez, Milfont e Belo (2001), as pessoas interligam a palavra "lixo" aos males que este causa aos seres humanos e ao meio ambiente, tais como doenças e poluição. Entretanto, as definições referentes ao lixo, citadas pelos entrevistados, são mais relacionadas à reciclagem, ou seja, a maioria das pessoas relaciona o lixo a algo sustentável a algo prejudicial. Fato que foi constatado nos resultados encontrados na pesquisa, uma vez que 14\% dos entrevistados tiveram essa concepção ligada à sustentabilidade, enquanto $10 \%$ relacionaram a problemas ocasionados pelo lixo.

Apenas $6 \%$ dos alunos consideraram o lixo a partir de uma visão mais simplista, sendo considerado apenas algo "orgânico ou inorgânico".

Embora a definição do lixo seja considerada simples, esta deve ser bem definida, para que as pessoas possam associar o lixo à reutilização e prevenção. Assim, a definição de lixo deve ser associada à realidade, para que se possa realizar a manipulação desde o consumo até o gerenciamento correto dos resíduos sólidos (SILVEIRA; MORAES, 2007). 
O restante (6\%) apresentou definições diversas que não se enquadram nas demais já citadas. Dentre elas:

Lixo é onde coloca as coisas que não usamos mais, sendo um meio para preservar a natureza (R6).

Lixo é o que usamos no dia a dia, o que consumimos (R7).

No argumento de "R7" vê-se que um (a) do (a) s participantes da pesquisa, relacionou o lixo ao uso, ou seja, ao que se consome na sociedade. Dib-Ferreira (2005), explica que poucas pessoas definem o lixo como algo que é consumido e utilizado rotineiramente pelos seres humanos.

Em relação à frequência de aulas que abordam a temática "lixo", apenas 7\% relatou haver a constância desse conteúdo nas aulas, o restante relatou que o tema nunca ou raramente foi trabalhado na sala de aula. As aulas de educação ambiental são importantes para a formação dos discentes, tanto em aspectos educacionais, como sociais. Entretanto, vê-se que pouco se aborda a educação ambiental na sala de aula, corroborando com achados de Menezes (2014), em que a educação ambiental é pouco discutida nas aulas, ocasionando em conhecimentos básicos por parte dos discentes.

Para Castoldi, Bernardi e Polinarski (2009), os docentes se sentem desmotivados para trabalhar temas relacionados ao meio ambiente na sala de aula devido: a não valorização da profissão, a carga horária elevada de atividades e a falta de interesse dos alunos. Assim, o professor não aprofunda os temas, perfazendo uma explicação simplista e pouco explorada.

Buscou-se averiguar quais maneiras os estudantes consideravam melhores na minimização da quantidade de lixo (os discentes poderiam optar por mais de uma alternativa), e constatou-se que 50\% das respostas foram relacionadas à coleta seletiva, ou seja, à diminuição dos resíduos. $\mathrm{Na}$ percepção dos alunos será mais efetiva através deste processo. As outras opções citadas (ambas com 42\%) foram reciclagem e reutilização de materiais usados. As alternativas com porcentagens inferiores foram: maior quantidade de aterros (3\%), incineração (4\%) e diminuição de consumo de bens materiais (11\%). 
A coleta seletiva é um meio bastante comum nas cidades brasileiras, fornece empregos, permite a diminuição da poluição no espaço urbano e permite a produção de novos materiais. Furiam e Günther (2006) relatam que a coleta seletiva é um meio pelo qual as pessoas são conscientizadas, principalmente no que se refere à separação e utilização dos resíduos na produção de outros materiais. Entretanto, percebe-se que apesar da sensibilização promovida por tal prática, a questão da redução do consumo para minimizar a quantidade de resíduos, não é entendida e tão pouco incorporada nas ações comportamentais.

A reciclagem e a reutilização são alternativas viáveis para a minimização do lixo. Há um grande número de utilidades que os produtos gerados por tais ações apresentam, e ainda há a contribuição do bem realizado ao meio ambiente (MAGALHÃES, 2002). Para Dib-Ferreira (2005), a reciclagem para minimização da quantidade de lixo é uma alternativa muito relatada pelas pessoas, porém, se o processo de consumo continuar cada vez mais constante, apenas a reciclagem não proporcionará a devida sustentabilidade.

A incineração do lixo e aumento de quantidade de aterros, são alternativas menos favoráveis ao meio ambiente, uma vez que a queima dos resíduos lança na atmosfera gases poluentes e os aterros por maior quantidade que existam, sempre acumularão cada vez mais lixo, já que o consumo de bens não cessa. Assim como Magalhães (2002) confirma essa concepção, ao relatar que a incineração traz emissões prejudicais e desagradáveis, e ainda apresenta custos elevados. As alternativas que restam, já que a produção de resíduos é inevitável, é a redução da geração de lixo (consumismo) e a reciclagem deste.

Pereira e Maia (2012) em estudos dissertam sobre a questão dos aterros, que apesar de haver pesquisas que relatem sobre a produção de energia por meio de aterros, estas, não representam uma solução isolada para o problema existente referente à exorbitante quantidade de lixo presente na terra. A implementação dos aterros ainda envolve diversos fatores, tais como verba, sociedade, estado e indústrias privadas. Os maus hábitos que envolvem a questão dos resíduos são evidenciados pela falta de 
conscientização, sendo necessário haver um processo reflexivo que envolva a mudança das ações humanas.

Nota-se que os discentes, por vezes, detêm de um conhecimento equívoco sobre a questão do lixo, e para Almeida e Lopez (2012), isso ocorre porque a educação ambiental é trabalhada com algumas falhas. Esse problema necessita ser mudado o mais rápido possível, pois a realidade ambiental atual deve ser integrada aos aspectos sociais existentes.

O fator correspondente à baixa porcentagem de estudantes que optaram pela alternativa referente à diminuição de consumo de bens materiais na minimização do lixo pode ser explicada por Cardoso, Frenedozo e Araújo (2015). As escolas apresentam alguns fracassos relacionados à educação ambiental e aos aspectos da atualidade que envolvem a temática. Isso ocorre devido a falta de teoria e metodologia por parte dos docentes. Magalhães (2002) ainda expõe a questão da redução como uma atividade mais difícil de ser implementada e entendida pela sociedade, uma vez que envolve a liberdade e felicidade das pessoas na aquisição de bens materiais quando e o quanto quiser.

Os resultados demonstram que a educação ambiental é vista em poucas disciplinas, o que demonstra que não é trabalha interdisciplinarmente. As disciplinas citadas pelos discentes nas quais os professores abordaram a temática "lixo" e suas vertentes foram poucas. $82 \%$ dos alunos afirmam terem visto esse conteúdo na matéria de Biologia. Outras disciplinas citadas foram: química $(30 \%)$, geografia $(27 \%)$, sociologia $(8 \%)$, filosofia $(2 \%)$ história e física (ambas com apenas 1\%).

Vê-se que nem todas as disciplinas abordam a educação ambiental e para Lins e Lisovski (2010) a escola pode até estimular os docentes a trabalhar o conteúdo com interdisciplinaridade, mas ainda é trabalhado em poucas disciplinas.

A educação ambiental precisa ser integrada em todas as disciplinas presentes na escola, pois para Quadros (2007) o meio ambiente e a sociedade devem ser trabalhados em todas as disciplinas. Um processo de ensino não fragmentado em todas as disciplinas resultará em uma 
aprendizagem mais frágil sobre as concepções socioambientais e a conscientização referente às práticas educativas coerentes.

A conscientização é um papel essencial na formação, dessa maneira, os estudantes foram indagados sobre os meios mais efetivos na conscientização sobre o lixo. E constatou-se que 58\% acreditam nos projetos de educação ambiental das escolas para a sensibilização das pessoas. Assim, para que estes ocorram, Bolzan e Gracioli (2012) acreditam que a escola deve incentivar os projetos que realizem atividades de cunho ambiental. Os projetos didáticos ainda, para Albrecht e Krüger (2013), representam práticas diferenciadas e voltadas à realidade dos alunos, fogem do tradicionalismo das aulas e fazem com que os discentes se interessem e se motivem mais.

Observou-se que os meios de comunicação são pouco referidos (11\%) como métodos de conscientização pelos alunos, porém, para Soffa e Torres (2009) as tecnologias de informação e comunicação (TICs) são ferramentas educacionais que podem ser usadas na educação. Para Amante (2007) as TICs facilitam o conteúdo e tornam-se essenciais na construção do conhecimento.

A escolha do livro didático foi vista em $10 \%$ das respostas dos estudantes. Para Oliveira, Obara e Rodrigues (2007) isso reflete a ligação aos conceitos predispostos que os livros de biologia contêm. São vistos como "chatos" pelos discentes, pois não promovem uma interação direta com o que está sendo estudado e muitas vezes são limitados em conteúdo.

Outras soluções plausíveis, segundo os discentes, seriam as ações governamentais (com 54\%). Para Coutinho (2009), o estado tem um papel de resguardar o meio ambiente para a população atual e para as próximas gerações. Assim, as políticas de desenvolvimento são importantes na proteção do meio ambiente, e devem atender ao interesse público, ou seja, devem disponibilizar benefícios e mecanismos que visem o bem comum.

É notável a necessidade de ações públicas do governo relacionadas à educação ambiental. Entretanto o autor ressalta ainda que apesar de haver políticas de cunho ambiental no Brasil, poucas destas são relacionadas especificamente aos resíduos sólidos (BROLLO, 2001). 
Os discentes ainda foram indagados sobre o meio pelo qual obtiveram o conhecimento sobre os resíduos sólidos, constatou-se que $69 \%$ afirmam ter aprendido sobre o lixo nas aulas de biologia. Todavia, esses resultados se contrapõem aos citados anteriormente, já que apenas $7 \%$ dos alunos afirmaram ter aulas que abordem o conteúdo referente ao lixo. Para Barboni (2014), este fato é ocasionado devido a ligação que a disciplina de biologia tem com os aspectos ambientais, com a natureza e meio ambiente.

Ainda de acordo com Barboni (2014), as aulas de ciências chamam bastante atenção dos discentes. Assim, trabalhar conteúdos referentes às questões ambientais no ensino de Biologia permite aprimorar e prolongar o conhecimento dos alunos.

Pode-se notar que alguns dos entrevistados escolheram alternativas que correspondem às ferramentas tecnológicas no aprendizado sobre o tema "lixo". Para Cruz (2008), estamos em uma sociedade caracterizada pela informação rápida e dinâmica, de modo que, quem usufrui destes meios aprende de forma significativa, uma vez que a aprendizagem passa a ser construtiva por cada um que se utiliza das tecnologias de informação e comunicação.

A televisão e o rádio possibilitam aos discentes o acompanhamento dos problemas ambientais existentes no mundo, porém, mesmo assim, boa parte dos alunos não apresentam noções claras sobre questões ambientais, e tampouco associação ao que veem com a realidade do local onde estão inseridos (CASTOLDI; BERNARDI; POLINARSKI, 2009).

Outro meio citado por discentes foi o livro didático, foi o segundo menos mencionado (Figura 1). Para Cardoso, Frenedozo e Araújo (2015) recorrentemente os livros abordam o meio ambiente, como sendo algo perfeito, sem problemas, assim os discentes assumem uma percepção "romântica" da natureza. 


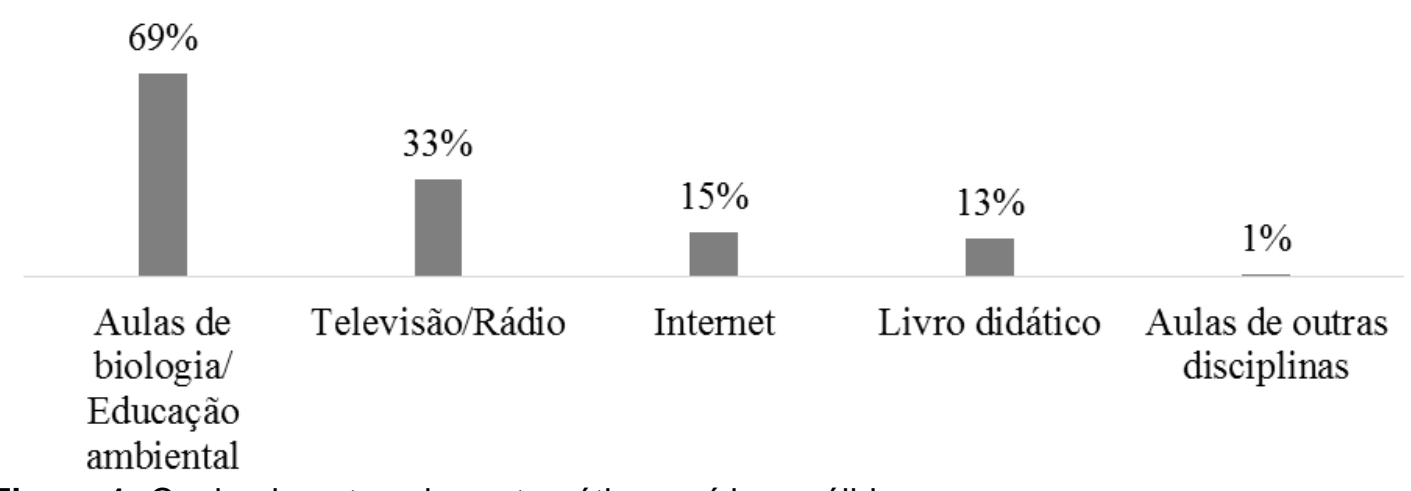

Figura 1: Conhecimento sobre a temática resíduos sólidos

Fonte: Elaborada pelos autores.

\section{Considerações finais}

O estudo demonstrou que mais da metade dos discentes atribui ao lixo termos que não estão ligados à sustentabilidade. De modo que, poucos relacionam a palavra lixo aos aspectos culturais existentes no campo social onde estão inseridos.

A frequência de aulas que abordam a temática "lixo" é considerada baixa pelos próprios discentes. Entretanto, a maioria destes, obteve o conhecimento sobre o tema na sala de aula, principalmente na disciplina de Biologia. A geografia e química foram outras disciplinas bem citadas, o que demonstra um indício de interdisciplinaridade no contexto escolar. A visão sobre a minimização do lixo é interligada à coleta seletiva, reciclagem e a reutilização. São todas opções favoráveis e contribuintes ao meio ambiente, muito embora, poucos alunos apresentem um conceito menos simplista sobre a questão.

Referindo-se à conscientização, os discentes acreditam que a educação é fator preponderante para tal realização, sendo as aulas, projetos de educação ambiental e campanhas educacionais do governo mais referidas como eficientes no processo de sensibilização.

A presente pesquisa constatou que a temática resíduos sólidos é pouco abordada na escola, o que possivelmente esclarece a pouca informação que os estudantes detêm e o conhecimento superficial sobre o lixo e suas vertentes no contexto social. É essencial a contribuição dos discentes na resolução de problemas ambientais, mas para que isso seja possível é necessário o 
aprofundamento dos pressupostos da educação ambiental em vários âmbitos da sociedade, sendo o ambiente escolar um desses.

\section{Referências}

ALBRECHT, L. D.; KRÜGER, V. Metodologia tradicional x Metodologia diferenciada: a opinião de alunos. Revista Unijuí, ljuí, n. 33, 2013.

ALENCAR, M. M. M. Reciclagem de lixo numa escola pública do município de salvador. Candombá, Bahia, v. 1, n. 2, p. 96-113, dez. 2005. ISSN 1809-0362.

ALMEIDA, D. N.; LOPEZ, M. R. Q. Estudo sobre a produção e destino do lixo doméstico. In: PARANÁ. Secretaria de Estado da Educação. Superintendência de Educação. O professor PDE e os desafios da escola pública paranaense. Curitiba: SEED/PR., 2012. (Cadernos PDE).

AMANTE, L. As TIC na Escola e no Jardim de Infância: motivos e factores para a sua integração. Sísifo. Revista de Ciências da Educação, n. 3, p. 51-64, maio/ago. 2007. ISSN 1649-4990.

BARBONI, K. de O. Lixo e reciclagem nas escolas - levando as novas gerações a um projeto de vida sustentável. 2014. 24 f. Monografia (Especialização em Ensino de Ciências) - Pólo de Goioerê, Modalidade de Ensino A Distância, Universidade Tecnológica Federal do Paraná, Medianeira, 2014.

BAUER, M. W.; GASKELL, G. Pesquisa qualitativa com texto, imagem e som: Um manual prático. Traduzido por Pedrinho A. Guareschi. Petrópolis: Vozes, 2002.

BOFF, E. T. de O; ARAúJO, M. C. P de; BOFF, E. de O. Educação ambiental e significação dos conceitos científicos para constituição de uma nova consciência. Revista de Didácticas Específicas, Madri, v. 1, n. 1, p.222-243, out. 2009. ISSN: 1989-5240. 
BOLZAN, A. Z.; GRACIOLI C. R. Ações de educação ambiental na escola municipal de ensino fundamental João Pessoa - São Sepé, RS. Revista Eletrônica em Gestão, Educação e Tecnologia Ambiental, Santa Maria, v. 6, n. 6, p.1007-1014,2012. ISSN: 2236-1170.

BROLLO, M. J. Metodologia automatizada para seleção de áreas para disposição de resíduos sólidos: Aplicação na região metropolitana de Campinas (SP). 2001. 213 f. Tese (Doutorado em Saúde Ambiental) Departamento de Saúde Ambiental, Faculdade de Saúde Pública da Universidade de São Paulo, São Paulo, 2001.

CAMPOS, F. G. G.; SANTOS, R. F.; SANTOS, F. C. P. e. A importância da pesquisa científica na formação profissional dos alunos do curso de educação física do unilestemg. Revista Digital de Educação Física, Ipatinga, v. 4, n. 2, p.1-11, ago./dez. 2009.

CARARO A. et al. A conscientização ambiental e a prática de separação de resíduos sólidos de acadêmicos da UTFPR. Synergismus Scyentifica UTFPR, Pato Branco, v. 3, n. 1, p. 1-5. 2008. ISSN: 2316-4689.

CARDOSO, F. de A.; FRENEDOZO, R. de C.; ARAÚJO, M. S. T. de. Concepções de meio ambiente entre estudantes de licenciatura em ciências biológicas. Revista Brasileira de Educação Ambiental, São Paulo, v. 10, n. 2, p.95-112, 2015.

CASTOLDI, R.; BERNARDI, R.; POLINARSKI, C. A. A Percepção dos problemas ambientais por alunos do ensino médio. Revista Brasileira de Ciências, Tecnologia e Sociedade, Alagoas, v. 1, n. 1, p.56-80, 2009.

CHAER, G.; DINIZ, R. R. P.; RIBEIRO, E. A. A técnica do questionário na pesquisa educacional. Evidência, Araxá, v. 7, n. 7, p. 251-266, 2011.

CORTEZ, J. C. V.; MILFONT, T. L.; BELO, R. P. Significado psicológico do lixo: um estudo com redes semânticas naturais. Programa de Pós-Graduação Stricto Sensu em Psicologia, São Francisco, v. 6, p.21-28, 2001. 
COUTINHO, N. C. de A. Poder público e a proteção ao meio ambiente. Colloquium Humanarum, Presidente Prudente, v. 6, n. 2, p.59-66, jul./dez. 2009.

CRUZ, J. M.de O. Processo de Ensino-Aprendizagem na Sociedade da Informação. Educação \& Sociedade, Campinas, v. 29, n. 105, p.1023-1042, set./dez. 2008.

DIAS, V. L. N. et al. Educação ambiental. In: CONGRESSO BRASILEIRO DE EXTENSÃO UNIVERSITÁRIA, 6., 2014, Belém. Anais.... Pará: UFPA, 2014. p. $87-90$.

DIB-FERREIRA, D. R. As diversas visões do lixo. 2005. 160 f. Dissertação (Mestrado em Ciência Ambiental) - Instituto de Geociências, Universidade Federal Fluminense, Niterói, 2005.

FERNANDES, N. de A. Os reflexos da modernidade na geração de resíduos: uma análise do fenômeno da globalização à luz da Política Nacional de Resíduos Sólidos. In: LEITE, J. R. M. (Org.); BELCHIOR G. P. N. (Org.). Resíduos Sólidos e Políticas Públicas: Diálogos entre Universidade, Poder Público e Empresa. Florianópolis: Insular, 2014. Cap. 8, p. 299. ISBN: 978-857474-749-1.

FERREIRA, J. A.; ANJOS, L. A. dos. Aspectos de saúde coletiva e ocupacional associados à gestão dos resíduos sólidos municipais. Caderno de Saúde Pública, Rio de Janeiro, vol. 17, n. 3, p. 689-696, maio/jun. 2001.

FRANCO, P. R. Sociedade de consumo e educação ambiental: breve reflexão acerca da vulnerabilidade da criança e a educação ambiental como instrumento de mudança. In: LEITE, J. R. M. (Org.); BELCHIOR, G. P. N. (Org.). Resíduos Sólidos e Políticas Públicas: Diálogos entre Universidade, Poder Público e Empresa. Florianópolis: Insular, 2014. Cap. 10, p. 299. ISBN: 978-85-7474-7491. 
FURIAM, S. M.; GÜNTHER W. R. Avaliação da educação ambiental no gerenciamento dos resíduos sólidos no campus da universidade estadual de feira de Santana. Sitientibus, Feira de Santana, n.35, p.7-27, jul./dez. 2006.

INSTITUTO DE PESQUISA E ESTRATÉGIA ECONÔMICA DO CEARÁ (IPECE). Perfil básico municipal 2015 - Crateús. Fortaleza-Ce, 2015. Disponível em: <http://www.ipece.ce.gov.br/publicacoes/perfil_basico/pbm2015/Crateus.pdf>. Acesso em: 12 de fev. 2016.

LINS, R. B.; LISOVSKI, L. A. Educação ambiental na escola: o trabalho desenvolvido por professores de um colégio do interior do Paraná. Olhar de professor, Ponta grossa, v. 1, n. 1, p. 171-184, 2010.

MAGALHÃES, L. M. Lixo e desperdício, perspectiva numa sociedade de consumo. 2002. 47 f. Monografia (Especialização em de Marketing Globalizado) - Instituto de Pesquisas Sociopedagógicas, Universidade Candido Mendes, Rio de Janeiro, 2002.

MARCONI, M. de A.; LAKATOS, E. M. Fundamentos da metodologia científica. 5 ed. São Paulo: Atlas, 2003.

MENEZES, J. B. F. de. Educação ambiental como prática pedagógica em uma escola de ensino fundamental na cidade de Acopiara -CE In: V ENEBIO E II EREBIO REGIONAL, 7., 2014, Acopiara. Anais... São Paulo: Sbenbio, 2014. p. 4194 - 4202.

NAVARRO, G. C. Educação ambiental e resíduos sólidos. In: LEITE, José Rubens Morato (Org.); BELCHIOR, G. P. N. (Org.). Resíduos Sólidos e Políticas Públicas: Diálogos entre Universidade, Poder Público e Empresa. Florianópolis: Insular, 2014. Cap. 5, p. 299. ISBN: 978-85-7474-749-1.

OLIVEIRA, A. L. de; OBARA, A. T.; RODRIGUES, M. A. Educação ambiental: concepção e práticas de professores de ciências no ensino fundamental. Revista Electrônica de Ensañanza de La Ciencia, v. 6, n. 3, p. 471-495, 2007. 
OLIVEIRA, Michele Morais. et al. A sobrevivência como foco: cotidiano e perspectivas de futuro dos catadores de materiais recicláveis. Oikos: Revista Brasileira de Economia Doméstica, Viçosa, v. 22, n. 1, p.6-24, jun. 2011.

OLIVEIRA, N. A. da S. A percepção dos resíduos sólidos (lixo) de origem domiciliar, no bairro cajuru-curitiba-pr: um olhar reflexivo a partir da educação ambiental. 2006. 173 f. Dissertação (Mestrado Acadêmico em geografia) - Curso de Geografia, Universidade Federal do Paraná, Curitiba, 2006.

PEREIRA, A. L.; MAIA, K. M. P. A contribuição da gestão de resíduos sólidos e educação ambiental na durabilidade de aterros sanitários. Sinapse Múltipla, Minas, v. 1, n. 2, p.68-80, dez. 2012. ISSN 2316-4514.

PIAZ, J. F. dal; FERREIRA, G. M. V. Gestão de resíduos sólidos domiciliares urbanos: o caso do município de Marau - RS. Revista de Gestão Social e Ambiental, São Paulo, v. 5, n. 1, p.33-47, jan./abr. 2011.

PRODANOV, C. C.; FREITAS, E. C. de. Metodologia do trabalho científico: Método e técnicas de pesquisa e do trabalho acadêmico. 2. ed. Novo Hamburgo: Universidade FEEVALE, 2013. 276 p.

QUADROS, A.de. Educação Ambiental: iniciativas populares e Cidadania.2007.46f. Trabalho de conclusão de Curso (Especialização em Educação Ambiental) - Universidade Federal Federal de Santa Maria (UFSM, RS), Santa Cruz, RS, 2007.

RAZZIA, S.; BIASUS, F. Representação social do lixo: um reflexo da perspectiva ambiental contemporânea. Vivências: Revista Eletrônica de Extensão da URI, Rio Grande do Sul, v. 11, n. 20, p.118-133, maio 2015. ISSN 1809-1636.

RÊGO, R. de C. F.; BARRETO, M. L.; KILLINGER, C. L. O que é lixo afinal? Como pensam mulheres residentes na periferia de um grande centro urbano. Caderno de Saúde Pública, Rio de Janeiro, v. 6, n. 18, p.1583-1592, nov./dez. 2002. 
ROTH, C. das G.; GARCIAS, C. M. A influência dos padrões de consumo na geração de resíduos sólidos dentro do sistema urbano. Redes, Santa Cruz do Sul, v. 13, n. 3, p.5-13, set./dez. 2008.

SOFFA, M. M.; TORRES, P. L. O processo ensino-aprendizagem mediado pelas tecnologias da informação e comunicação na formação de professores on-line. In: IX CONGRESSO NACIONAL DE EDUCAÇÃO-EDUCERE \& III ENCONTRO SUL BRASILEIRO DE PSICOPEDAGOGIA., 9 e 3.,2009, Paraná. Anais...Paraná: PUCPR, out. 2009. P. 10424-10434.

YIN, R. K. Estudo de caso: planejamento e métodos. Tradução de Daniel Grassi. 2. ed. Porto Alegre: Bookman, 2001. 205 p.

ZANETI, I. C. B. B.; SÁ, L. M. A educação ambiental como instrumento de mudança na concepção de gestão dos resíduos sólidos domiciliares e na preservação do meio ambiente. In: I ENCONTRO ASSOCIAÇÃO NACIONAL DE PÓS GRADUAÇÃO E PESQUISA EM AMBIENTE E SOCIEDADE, 1., 2002, Indaiatuba. Anais.... Indaiatuba - SP: Anppas, 2002. p. 1 - 10. 